\title{
Erratum to: Spin Wave Frequency Variations Due to the Spin Glass Behavior in Co/CoPt Magnetic Multilayers
}

\author{
A. Bakhshayeshi ${ }^{1} \cdot$ R. Taghavi Mendi ${ }^{1} \cdot$ F. Parhizkar Khadiv ${ }^{1}$
}

Published online: 19 May 2017

(C) Springer Science+Business Media New York 2017

Erratum to: J Supercond Nov Magn (2017)

DOI 10.1007/s10948-017-4107-4

The original version of this article contained a mistake: the author name F. Parhizkar Khadiv was incorrectly written as F. Parhizgar Khadiv.

The original article has been corrected.

The online version of the original article can be found at http://dx.doi.org/10.1007/s10948-017-4107-4

\footnotetext{
A. Bakhshayeshi

bakhshayeshi.ali@gmail.com

1 Islamic Azad University Mashhad Branch,

Department of Physics, Mashhad, Iran
} 